Original Article

\title{
PHYTOCHEMICAL ANALYSIS AND IN VITRO DPPH ASSAY OF ETHANOLIC EXTRACT OF MUCUNA PRURIENS SEED
}

\author{
SREEKALA V.1 ${ }^{*}$, VIJAYKISHAN B., S. S. RAJASEKAR, RAJESH R. \\ 1Department of Dravyaguna, Faculty of Ayurveda, Institute of Medical Sciences, Banaras Hindu University, Varanasi 221005, \\ 2,3,4Department of Anatomy, N R I Institute Medical Sciences, Visakhapatnam 531163 \\ Email: rajesh2361@gmail.com
}

Received: 15 Jul 2020, Revised and Accepted: 08 Sep 2020

\begin{abstract}
Objective: To detect the bioactive phytoconstituents of Mucuna pruriens seed extract and to estimate invitro antioxidant activity.

Methods: Preliminary phytochemical analysis were done to determine the active phytochemical constituents and DPPH (2, 2-diphenyl-1picrylhydrazyl) assay method was used for the estimation of In vitro antioxidant activity.

Results: Preliminary phytochemical analysis of Mucuna pruriens seed extract showed the presence of chief bioactive components like phenols, flavonoids, tannins, alkaloids, triterpenes and phytosterols. In antioxidant assay, Mucuna pruriens seed extract exhibited a maximum DPPH radical scavenging activity of $72.95 \%$ against the standard control with a maximum activity of $93.24 \%$ for the same concentration $(0.2 \mathrm{mg} / \mathrm{ml})$. This is a
\end{abstract} clear indication of strong antioxidant property of the drug.

Conclusion: Mucuna Pruriens seeds are abundant source of natural antioxidants, and important bioactive phytoconstituents.

Keywords: Mucuna pruriens, Reactive oxygen species, In vitro antioxidant activity, DPPH assay, Natural antioxidants, Flavonoids

(c) 2020 The Authors. Published by Innovare Academic Sciences Pvt Ltd. This is an open access article under the CC BY license (http://creativecommons.org/licenses/by/4.0/) DOI: http://dx.doi.org/10.22159/ijcpr.2020v12i6.40300. Journal homepage: https://innovareacademics.in/journals/index.php/ijcpr

\section{INTRODUCTION}

Since prehistoric times, plants have been a plentiful source of drugs. Nowadays medicinal plants continue to serve as an important source of novel bioactive compounds which revolutionized the treatment of wide spectrum of diseases. The continued search for plant secondary metabolites as natural antioxidants has gained momentum in recent years.

In living systems, aerobic metabolism and environmental stresses generate free radicals, mainly reactive oxygen species (ROS) [1]. Amplified ROS levels can damage structure of biomolecules and in turn alters their functional characteristics, lead to cellular dysfunction and even cell death [2]. The cumulative effect of increased ROS induces oxidative stress in organ systems and play a crucial role in the pathogenesis of cancer, cardiovascular diseases and various age related and neurodegenerative disorders like Parkinson's disease [35]. These Cellular ROS are regulated by interaction of complex antioxidant machineries in living systems [6]. Nature itself has bestowed living systems with numerous antioxidant molecules, that enhances antioxidant capacity of the plasma and minimise the opposing effects of free radicals in living system thus aiding as an important therapeutic agent against degenerative diseases [7].

Mucuna Pruriens Linn. belonging to Fabaceae family is one of the prevalent and broadly used drug in the alternate system of medicine. The seeds of M. pruriens were found to be therapeutically effective in various conditions like impotence and neurological disorders [8]. Previous research studies on the M. pruriens seeds reported about the antidiabetic, anti-inflammatory, antipyretic, antiparkinsonian and aphrodisiac properties $[9,10]$. The efficacy of its seed in degenerative disorders irradiates a wide area of research by exploring the multifaceted pharmacotherapeutics. Based on these ethnomedicinal leads, the present study was undertaken to determine the phytoconstituents and to evaluate the antioxidant activity of Mucuna pruriens seed extract.

\section{MATERIALS AND METHODS}

\section{Collection and authentication of plant material}

The seeds of Mucuna pruriens were obtained from Department of Dravyaguna Vijnana, VPSV Ayurveda College, Kottakkal. The drug was identified and authenticated by Dr. Sreekala. K, Senior Scientist, Centre for Medicinal Plant Research, Aryavaidyasala, Kottakkal. The seeds were washed, shade dried and powdered.

\section{Preparation of extract}

Powdered drug was subjected to cold alcoholic extraction with ethanol in 1:3 ratio. $2 \mathrm{~kg}$ of the coarse powder of seeds of Mucuna Pruriens was taken in an aspirator bottle, 6 litres of ethanol added and this mixture shaken occasionally for $72 \mathrm{~h}$. Then the extract was filtered by using Whatman No.1filter paper on a Buchner funnel for three times before decanting and pooling. The solvent removed by vacuum distillation in a rotary evaporator at $40{ }^{\circ} \mathrm{C}$.

\section{Preliminary phytochemical analysis}

The ethanolic extract of test drug was subjected to preliminary phytochemical analysis for the detection of bioactive constituents using standard procedures described in 'Trease and Evans' Pharmacognosy, 16th edition [11].

\section{Test for steroids}

First the alcoholic extract of test drug was mixed with minimum quantity of choloroform. Then 3-4 drops of acetic anhydride and one drop of concentrated $\mathrm{H} 2 \mathrm{SO} 4$ was added. Formation of purple colour that changed in to blue or green indicated the presence of steroids.

\section{Test for triterpenoids}

Noller's Test: The substance was warmed with tin and thionyl chloride. Pink coloration indicated the presence of triterpenoids.

\section{Test for reducing sugars}

The test sample was mixed with Fehling's solutions II and I. Formation of red color precipitate indicated the presence of reducing sugars.

\section{Test for glycosides}

The alcoholic extract of Mucuna pruriens seed was mixed with a little anthrone on a watch glass. One drop of concentrated sulphuric acid was added, made into a paste and warmed gently over water bath. Dark green colour was appeared which indicated the presence of glycosides. 


\section{Test for alkaloids}

To the test substance few drops of acetic acid was added, followed by Dragendorff's reagent and shaken well. Formation of orange-red color precipitate indicated the presence of alkaloid.

\section{Test for phenolic compounds}

The extract was dissolved in alcohol and then added a drop of neutral ferric chloride (5\%). Development of intense blue colour indicated the presence of phenolic compounds.

\section{Test for catechin}

To the test substance in alcohol, Ehrlich's reagent was added followed by few drops of concentrated $\mathrm{HCl}$. Formation of pink colour indicated the presence of catechins.

\section{Test for saponins}

The substance was shaken with water. Copious lather formation indicated the presence of saponins.

\section{Test for flavonoids}

Shinado's Test: To the substance in alcohol, a few magnesium turnings and few drops of concentrated hydrochloric acid were added and boiled for five minutes. Red colour showed the presence of flavonoids.

\section{Test for tannins}

The alcoholic extract of test sample mixed with basic lead acetate solution. Formation of white precipitate indicated the presence of tannins.

\section{Test for anthroquinones}

To the test substance, magnesium acetate solution was added. The presence of anthroquinones indicated by the development of pink colour.

\section{In vitro antioxidant assay}

In vitro DPPH assay was done to estimate the antioxidant activity of ethanolic extract of Mucuna Pruriens seed using the standard method. [12] A solution of $0.1 \mathrm{~mm}$ DPPH was prepared and $1 \mathrm{ml}$ of this solution was added to $1 \mathrm{ml}$ of four different concentrations $(0.025 \mathrm{mg} / \mathrm{ml}, 0.05 \mathrm{mg} / \mathrm{ml}, 0.1 \mathrm{mg} / \mathrm{ml}$ and $0.2 \mathrm{mg} / \mathrm{ml})$ of the ethanolic extract of the test drug and $1 \mathrm{ml}$ of methanol. The reaction mixture was then incubated at room temperature in a dark chamber for $30 \mathrm{~min}$. The change in colour from deep violet to light yellow was noted and the absorbance of the mixture was measured at $517 \mathrm{~nm}$ using ultra violet spectrophotometer. Ascorbic acid was used as reference and DPPH solution in methanol was taken as the control. Estimation of the ability of test drug to scavenge DPPH free radical was calculated using the following formula

The percentage of DPPH radical scavenging activity $=[(\mathrm{Abs}$ control)-(Abs sample)]/(Abs control) x 100;

Where, Abs control is the absorbance of the control and Abs sample is the absorbance of samples.

\section{Principle of DPPH assay}

Scavenging of DPPH free radical is the basis of this antioxidant assay. DPPH (1, 1diphenyl-2-picryl hydrazyl) represents the stable free radical with Purple color. The Antioxidant scavenger molecule scavenges free radical from DPPH thereby DPPH accepting a hydrogen $(\mathrm{H})$ atom from antioxidant molecule resulting in the Reduction of DPPH to DPPH2. This produces change in color from purple to yellow with the associated decrease in absorbance at 515 $\mathrm{nm}$. This color change is monitored spectrophotometrically and the estimation of antioxidant property was done based on the formulae $[\mathrm{DPPH}+[\mathrm{H}-\mathrm{A}] \rightarrow \mathrm{DPPH}-\mathrm{H}+(\mathrm{A})]$.

\section{RESULTS}

\section{Preliminary phytochemical analysis}

The results of the preliminary phytochemical analysis of Mucuna pruriens is given in table 1 . Phytochemical analysis of mucuna pruriens seeds revealed the presence of phenolic compounds, flavonoids, tannins, alkaloids, glycosides, phytosterols, triterpenes, saponins and reducing sugars.

Table 1: Preliminary phytochemical screening of ethanolic extract of Mucuna Pruriens seeds

\begin{tabular}{llll}
\hline S. No. & Phytochemical analysis & Test & Result \\
\hline 1. & Test for Steroids & Salkowski test & Present \\
2. & Test for Triterpenoids & Noller's Test: & Present \\
3. & Test for Reducing sugars & Fehling's test & Present \\
4. & Test for Glycosides & Liebermann's Test & Present \\
5. & Test for Alkaloids & Dragendorff's test & Present \\
6. & Test for Phenolic compounds & Ferric chloride test & Present \\
7. & Test for Catechin & Ehrlich's test & Absent \\
8. & Test for Saponins & Foam test & Present \\
9. & Test for Flavanoids & Shinoda test & Present \\
10. & Test for Tannins & Gelatin test & \\
11. & Test for Anthraquinones & Borntrager's test & Absent \\
\hline
\end{tabular}

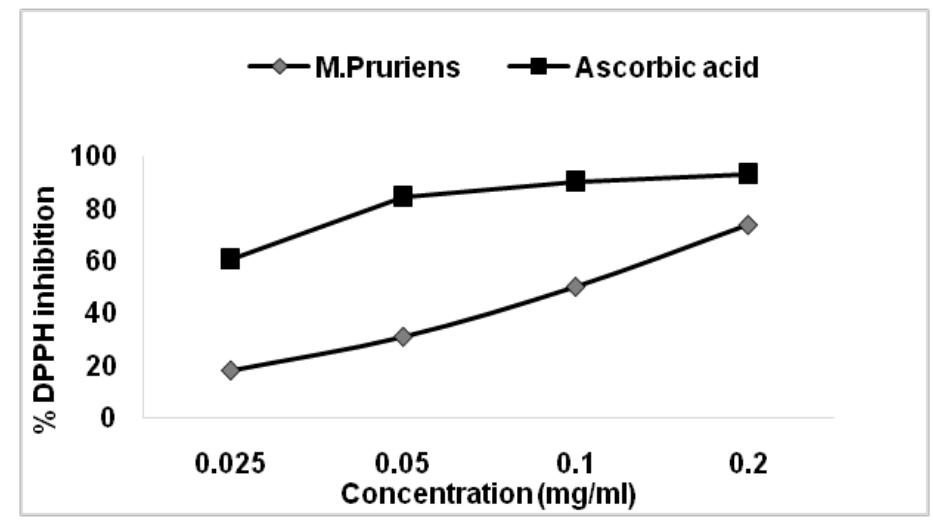

Fig. 1: DPPH radical scavenging activities of mucuna pruriens seed extract and ascorbic acid 


\section{In vitro DPPH antioxidant assay}

Mucuna pruriens seed extract showed DPPH radical scavenging activity of $18.24 \%, 31.13 \%, 50.27 \%$ and of $72.95 \%$ at different concentrations of $0.025 \mathrm{mg} / \mathrm{ml}, 0.05 \mathrm{mg} / \mathrm{ml}, 0.1 \mathrm{mg} / \mathrm{ml}$ and 0.2 $\mathrm{mg} / \mathrm{ml}$ respectively. The corresponding percentage of DPPH radical scavenging activity of reference control ascorbic acid were $60.79 \%, 84.65 \%, 90.41 \%$ and $93.24 \%$. Showed a maximum activity of $93.24 \%$ at the same concentration (table 2). A significant percentage inhibition of DPPH by mucuna Pruriens seed extract (72.95) was observed at the highest concentration of $0.2 \mathrm{mg} / \mathrm{ml}$ as represented in the fig. 1.

Table 2: Percentage DPPH radical inhibition of mucuna pruriens seed extract and Ascorbic acid at different concentrations

\begin{tabular}{lll}
\hline Concentrations tested $(\mathbf{m g} / \mathbf{m l})$ & \% DPPH radical inhibition & Ascorbic acid \\
\cline { 2 - 3 } & M. Pruriens seed extract & 60.79 \\
0.025 & 18.24 & 84.65 \\
0.05 & 31.13 & 90.41 \\
0.1 & 50.27 & 93.24 \\
\hline
\end{tabular}

\section{DISCUSSION}

\section{Phytochemical analysis}

In the present study, preliminary phytochemical analysis showed that the Mucuna Pruriens seeds possess bioactive ingredients like alkaloids, flavonoids, saponins, phenolic components, triterpenoids, steroids, reducing sugars, tannins and cardiac glycosides. Apart from this, it also contains high fibre content. This study supports the findings of Swamy et al. reported that ethanolic extract of mucuna seeds contain alkaloids, carbohydrates, flavonoids, steroids, amino acids, triterpenoids, saponin, tannin, protein and phenol [13]. While phytochemical evaluation of the methanolic extract of Mucuna Pruriens seeds by Hadimani et al. noted the absence of saponins and triterpenoids [14]. This variation in the phytochemical constitution may be attributed to the fact that genomic composition and ambient environmental conditions, harvesting techniques, postharvest processing, storage conditions, widespread use of pesticides, frequent adulteration and microbial contamination may result in notable variation in chemical profile of medicinal plant material [15].

\section{In vitro DPPH antioxidant assay}

Increased oxidative stress and Reactive oxygen species (ROS) formation damage the structure of biomolecules and modify their function. Natural antioxidants minimize the adverse effects of free radicals by scavenging action. It has beneficial effects in main tenance of health, management of age related diseases, ameliorating the harmful effects of toxic agents both chemical and physical [16].

Scavenging of DPPH free radical by the antioxidants in the test sample constitutes the basis of this antioxidant assay [17]. DPPH (1, 1diphenyl-2-picryl hydrazyl) is a stable free radical with red colour which turns yellow when scavenged. DPPH assay uses this character to estimate free radical scavenging activity. Antioxidants react with DPPH and reduce it to DPPH-H and as consequence the absorbance decreases. The degree of discoloration indicates the scavenging potential of the antioxidant compounds in terms of hydrogen donating ability. In the present study, the test drug showed a significant antioxidant activity while comparing with the standards used.

The therapeutic efficacy of herbal drugs largely depends on the different phytochemical compounds present in it [18]. The powerful antioxidant activity of Mucuna pruriens seed extract can be attributed to the diverse phytoconstituents present in the drug. Previous studies have already reported the antioxidant potential of many of these compounds. Tannins are important phytochemical compound that possess antioxidant properties [19]. Flavonoids possess membrane stabilizing properties and inhibit lipid peroxidation in liver, brain, pancreas etc [20]. Phenols have antioxidant properties which carry out their protective activity on cells either by checking the free radical generation or by scavenging the free radicals [21]. Various studies have reported the antioxidant and anti-inflammatory potentials of saponins [22, 23]. Bioactive components like alkaloids and phytosterols are also considered effective in conditions like stress and depression [24]. Tri terpenoids, and reducing sugars are known antioxidants with antiproliferative properties, used in cancer research $[25,26]$.
Various studies on Mucuna pruriens seeds as an active prophylactic and therapeutic agent for radiation counter measures, combating cancers and aged related diseases [27]. Can be ascribed to the potential antioxidant properties of the drug, as evident in the present study.

\section{CONCLUSION}

Present study justifies the therapeutic potentials of Mucuna pruriens seed extract as a strong antioxidant agent due to the presence of diverse bioactive components like phenols, flavonoids, tannins, alkaloids, triterpenes and phytosterols. The outcome of this study is relevant for further researches on Mucuna pruriens seed extract as a viable source of natural antioxidants with wide area of application in different fields of sciences.

\section{ACKNOWLEDGEMENT}

We are thankful to the faculty members of Department of Dravyaguna, VPSV Ayurveda College, Kottakkal for their valuable support.

\section{FUNDING}

Nil

\section{AUTHORS CONTRIBUTIONS}

All the authors have contributed equally.

\section{CONFLICT OF INTERESTS}

The authors have no conflict of interest to declare.

\section{REFERENCES}

1. Lobo V, Patil A, Phatak A, Chandra N. Free radicals, antioxidants and functional foods: impact on human health. Pharmacogn Rev 2010;4:118-26.

2. Nita M, Grzybowski A. The role of the reactive oxygen species and oxidative stress in the pathomechanism of the age-related ocular diseases and other pathologies of the anterior and posterior eye segments in adults. Oxid Med Cell Longev 2016;2016:3164734. DOI:10.1155/2016/3164734

3. Grune T, Shringarpure R, Sitte N, Davies K. Age-related changes in protein oxidation and proteolysis in mammalian cells. J Gerontol A Biol Sci Med Sci 2001;56:B459-67.

4. Noguchi N, Niki E. Phenolic antioxidants: a rationale for design and evaluation of novel antioxidant drug for atherosclerosis. Free Radical Biol Med 2000;28:1538-46.

5. Dias V, Junn E, Mouradian MM. The role of oxidative stress in Parkinson's disease. J Parkinsons Dis 2013;3:461-91.

6. Harris, Isaac S, Gina M DeNicola. The complex interplay between antioxidants and ROS in cancer. Trends in Cell Biology; 2020.

7. Devaraj, Sridevi. Supplementation with pine bark extract rich in polyphenols increases plasma antioxidant capacity and alters the plasma lipoprotein profile. Lipids 2002;37:931-4.

8. Lohiya NK, K Balasubramanian, AS Ansari. Indian folklore medicine in managing men's health and wellness. Andrologia 2016;48:894-907. 
9. Rajesh R. The effect of mucuna pruriens seed extract on pancreas and liver of diabetic wistar rats. Int J Curr Res Rev 2016;8:61.

10. Deokar, Gitanjali, Harshada Kakulte, Sanjay Kshirsagar. Phytochemistry and pharmacological activity of Mucuna pruriens: a review. Pharm Biol Evaluations 2016;3:50-9.

11. Evans, William Charles. Trease and evans' pharmacognosy Ebook. Elsevier Health Sciences; 2009.

12. Liyana Pathirana, Chandrika, Fereidoon Shahidi. Optimization of extraction of phenolic compounds from wheat using response surface methodology. Food Chem 2005;93:47-56.

13. Swamy, Gangadhara, Rajendra Holla, Suresh R Rao. A preliminary investigation for standardization of hydroalcoholic extract of mucuna pruriens (Kapikaccu): an important drug used to treat parkinson's disease in ayurveda. J Health Allied Sci NU 2019;9:85-90.

14. Hadimani, Gavishiddappa A. Evaluation of acute oral toxicity and phytoconstituents of methanolic extract of Mucuna pruriens. J Pharma Sci Res 2015;7:33-6.

15. Dhami N, Mishra AD. Phytochemical variation: how to resolve the quality controversies of herbal medicinal products? J Herbal Med 2015;5:118-27.

16. Pham Huy LA, He H, Pham Huy C. Free radicals, antioxidants in disease and health. Int J Biomed Sci 2008;4:89-96.

17. Sharma, Om P, Tej K Bhat. DPPH antioxidant assay revisited. Food Chem 2009;113:1202-5.

18. Kennedy JF, Thorley M. Pharmacognosy, phytochemistry, medicinal plants. $2^{\text {nd }}$ ed. Carbohydrates and Polymers; 2000;42:428-9.

19. Kumari M, Jain S. Tannins: an antinutrient with positive effect to manage diabetes. Res J Recent Sci 2012;1:70-3.
20. Rajesh R, Kotasthane DS, KM, Singh A, VS, Rajasekar SS. Histopathological and Histomorphometric analysis of Pancreas and liver of diabetic rats treated with mucuna pruriens seed extract. Annals Pathol Laboratory Med 2017;4:A546-52.

21. Uttara, Bayani. Oxidative stress and neurodegenerative diseases: a review of upstream and downstream antioxidant therapeutic options. Curr Neuropharmacol 2009;7:65-74.

22. Jang, Kyung Jun. Anti-inflammatory potential of total saponins derived from the roots of panax ginseng in lipopolysaccharide-activated RAW 264.7 macrophages. Exp Ther Med 2016;11:1109-15.

23. Rajesh R, Kotasthane DS, KM, Singh A, VS, Rajasekar SS Histopathological and histomorphometric analysis of pancreas and liver of diabetic rats treated with mucuna pruriens seed extract. Ann Pathol Lab Med 2017;4:A546-52.

24. Wu Yan-Qin. Long chain omega-3 polyunsaturated fatty acid supplementation alleviates doxorubicin-induced depressivelike behaviors and neurotoxicity in rats: involvement of oxidative stress and neuroinflammation. Nutrients 2016;8:243.

25. Bhandari, Jaya. Study of phytochemical, anti-microbial, antioxidant, and anti-cancer properties of Allium wallichii. BMC Complementary Alternative Med 2017;17:102.

26. Amico, Vincenzo. Antiproliferative terpenoids from almond hulls (Prunus dulcis): identification and structure-activity relationships. J Agric Food Chem 2006;54:810-4.

27. Minari JB, GO Ogar, AJ Bello. Antiproliferative potential of aqueous leaf extract of mucuna pruriens on DMBA-induced breast cancer in female albino rats. Egyptian J Med Human Genetics 2016;17:331-43. 